Volume 9, No.3, May - June 2020

International Journal of Advanced Trends in Computer Science and Engineering

Available Online at http://www.warse.org/IJATCSE/static/pdf/file/ijatcs242932020.pdf

https://doi.org/10.30534/ijatcse/2020/242932020

\title{
Bluetooth Smart based Automated Attendance System
}

\author{
Nesrine A. Azim ${ }^{1}$, Aisha Mohamed Hussein ${ }^{2}$, Hanan Ibrahim Shawky ${ }^{3}$, Heba Ahmed Joudah ${ }^{4}$ \\ ${ }^{l}$ Department of Information Systems and Technology, Faculty of Graduate Studies for Statistical Research, Cairo \\ University, Egypt. \\ ${ }^{2,3,4}$ Department of Computer Science, Faculty of Graduate Studies for Statistical Research, Cairo University, Egypt. \\ nesrinealiazim79@hotmail.com
}

\begin{abstract}
The management of student attendance during the lectures has become a challenging task. The rate of attending students registered has turned into a major assignment as manual calculation produces mistakes, and has become a timewasting activity. For the recently referenced reasons, a movable device is built, where in each lecture the student can register of his/her participation. The information entered is checked by utilizing remote RFID (Radio Frequency Identification) against the data contained in the RFID tag is expressed as the ID. The entered ID is sent through the sequential interface and began coordinating with the data stored in first Atmega AVR32 microcontroller. The "ID" showed on LCD and transmitted to the second Atmega AVR32 that interfaced with Bluetooth terminal and sent to an Android.
\end{abstract}

In this paper, we designed an application that takes electronically the attendance using Bluetooth. The application rectifies human errors, saves time and gives clear attendance to be used additionally in administrative decisions.

Key words: Atmega AVR, Bluetooth, Embedded system, Rapid Frequency Identification

\section{INTRODUCTION}

The majority of the instructive establishments and government use manual attendance system for the students. There are various drawbacks to this methodology, such as, analysis on this information cannot be performed due to questionable of credibility of the manual system, and it is time-consuming and error prone. There is a need to substitute the manual attendance method with automated attendance system. Recently, the Rapid Frequency Identification (RFID) [2], [6] systems have been widely used, especially in, medicine, transportation, agriculture.

The Internet of Things (IOT) [4], [8] technology utilizes the RFID [2], [6] systems by screening the in and out time of a student from any area. IOT [4], [8] utilizes a microcontroller [1], similar to a sensor, which will communicate with a mobile using the internet. In this paper, an embedded system application is developed for checking the attendance [5], [7], [8] of students within university. The hardware is embedded within the software which controls it through the microcontroller. RFID [2], [6] consists of RFID reader and RFID tag, which utilizes electromagnetic waves in order to communicate between its parts. Despite being better than previous manual systems, RFID [2], [6] has certain issues as well such as its complexity. As a result, the Bluetooth [8] information will be sent to mobile and saved in a database.

The proposed system will improve the work proficiency and will save human and material resources. The proposed system consists of two phases: First phase is the interface of RFID and AVR microcontroller [1]. Second phase is the interface of Bluetooth [8] terminal with the Android.

The remainder of the paper is sorted out as follow. Section 2 exhibits past research in attendance systems presently in use, states their advantages, disadvantages. Section 3 defines the design of the proposed system. Section 4 introduces the system implementation and results. Finally the conclusion and future work of this paper is in section 5 .

\section{RELATED WORK}

In [1] an automated attendance management system using RFID reader was implemented in mobile and electronic platform. Arduino board based on ATmega1280 was designed for fingerprint attendance system. ZFM 20 Fingerprint scanner with its own processor and memory was used. The user friendly interface was provided by TFT touch screen and SD card was used for storage of student's records with RTC (Real time clock) which provides the exact attendance date and time. Caesar Cipher cryptographic technique is used to secure the data against unauthorized user.

In [2], RFID based system identifies tags and is used to mark students' attendance using computer. The RFID reader detects the tag and the system processes the information on the computer according to the programmed instructions. The tractability, availability and receptiveness of the technology highly affect the ease with which RFID system can be integrated into current operations.

An alternate system for automatic student attendance that utilizes Fingerprint sensor/scanner was suggested in [3]. The system [3] uses 8051 microcontroller and R305 optical 
fingerprint sensor and LabVIEW Microcontroller communicates with PCs in which LabVIEW was installed on it. The LabVIEW is used for storing and maintaining the attendance records, and showing it to the user as well as the ID of the student is displayed on LCD if there is a match.

A secure hardware system was proposed by [4], which utilizes Internet of things that incorporates ARM9 S3C2440 processor board and FPS200 solid state fingerprint sensor. Database was designed using SQLite database. In addition to fingerprint biometric, Vein recognition [4] is also used. It monitors student attendance using a website but [4] suffers from complexity and high cost of system specifications.

In [5] a system consists of two sections: a transmitter and a receiver sections in addition to attendance supervision terminal. Transmitter section consists of optical fingerprint sensor OP-100N, ADSP-BF532 \& ZigBee transmitter, a signal processor consists of ZigBee receiver and microcontroller. Image enhancement is performed using MATLAB. MS-access and Visual basic are used for database implementation. The system requires three different supply voltages $(3.3 \mathrm{~V}, 5 \mathrm{~V}, 12 \mathrm{~V})$ but has low power consumption, cost efficient and wireless.

Another system which combines RFID and GSM technology with biometrics for attendance management was presented in [6]. Student ID is tagged with their RFID tag that matched with the database for attendance and fingerprint is verified using fingerprint sensor. Parents are notified about the attendance through SMS using GSM Modem. RFID transponders are installed in classrooms, laboratories and staffrooms through which location of the student and staff can be traced. Teachers and guardians can locate students in the campus and also can view the attendance record of the student through the website. The server application was programmed using vb.net and the web site was developed using asp.net.

NFC (Near Field Communication) based system was implemented in [7]. NFC based system has lower range than RFID based systems. The system is fully automated and secured but expensive, complex and the system should be 24/7 active.

\section{SYSTEM DESIGN}

\subsection{Proposed Model}

The AtmegaAVR32 microcontroller is pre-customized with Embedded $\mathrm{C}$ language utilizing programming Atmel studio 6.2. Concerning RFID [2], [6] all components are connected using power supply. If the tag is scanned, the tag must be close or in contact with RFID reader. The scanning time is roughly the same as the time to count the student manually in the class. The data contained in the RFID tag is expressed as the ID and attendance of the student. At the point when student put his card in front of RFID reader, it reads the data and begins to search with the data already stored in one AVR32 microcontroller [1]. The data (ID) will be shown on LCD after swipe the card. Next, the data is transmitted to the second AVR32 microcontroller [1] and interfaced with a HC05 Bluetooth module through UART serial communication protocol. Bluetooth [8] HC05 works with the Android application through Bluetooth as shown in Figure 1.

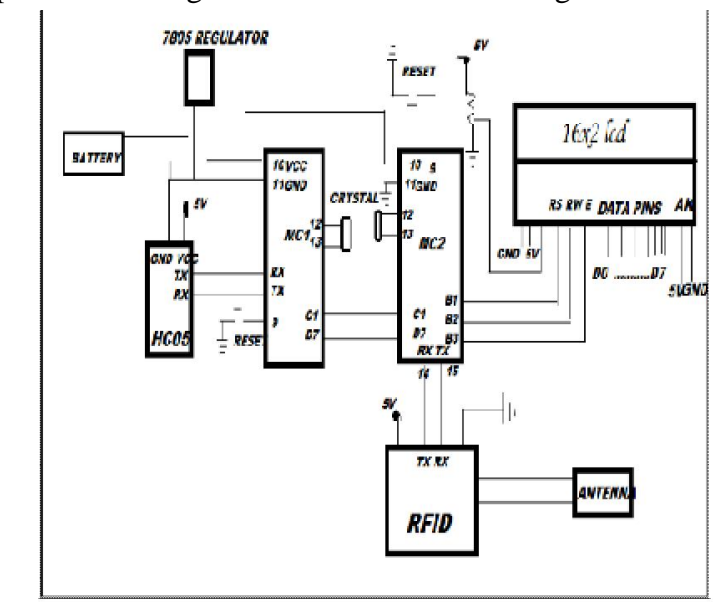

Figure 1: Block diagram of AVR32A wireless communication circuit

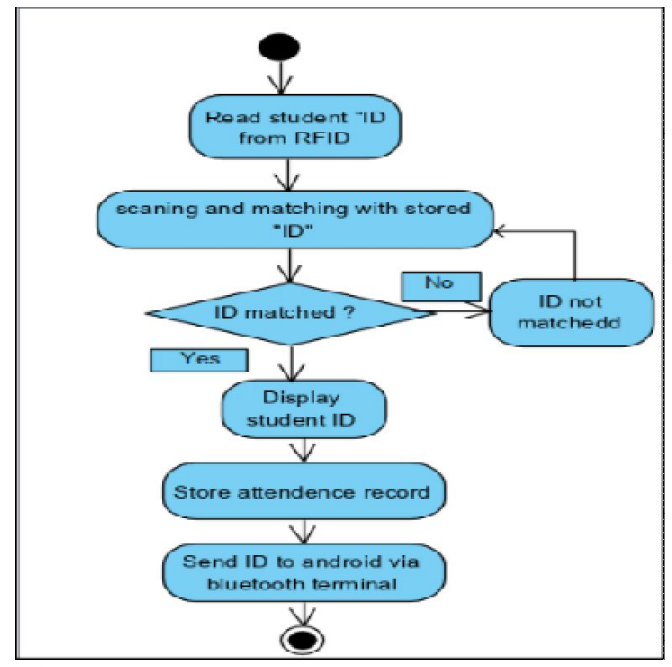

Figure 2: Activity diagram for attendance system

RFID tags can be embedded into the student ID card that require low power utilization, the tag can be read during motion where no line of sight is required for wireless communication between the tag and the reader.

The application recognizes tags just inside a specific range inside the class. Due to Bluetooth [8] chip that works in a range of $(2.4 \mathrm{GHz}-2.4835 \mathrm{GHz}$ ISM band) same as classic Bluetooth that supports high data transfer rate and low power utilization [8].

RFID tags are of 2 kinds: Passive tags contain 13 digit numbers built in it, and active tags are read/write tags. RFID reader contains a copper twisting in it that acts as antenna. 
The controller is loaded within a program. ASCII strings are sent to microcontroller which stores student information, via serial communication due to the interaction of tag with 12byte (characters) reader.

Student information is mainly tag number (ID) and name. When the circuit turns on the RFID [2], [6] based attendance is displayed on LCD. When 12 characters are sent to controller, the controller compares the characters with the saved one. If there is a match then controller sends ' 1 ' and displays student name otherwise the controller scans again as shown in Figure 2.

\subsection{The interface of Two ATmega AVR32 Microcontrollers}

The serial communication between two ATmega32 microcontrollers is UART (Universal Asynchronous Receiver Transmitter) as shown in Figure 3. UDR or USART Data Register is meant for writing and receiving the data through the UART. The TXD pin (data receiving feature) of first controller and RXD pin of second controller must be enabled for transmitter and for receiver. The program stops when complete byte is received. Data is transmitted and received to the controller in 8bits mode. This implies that, two characters are sent to the controller at once. There are no parity bits, only one stop bit for the data sent by the module.

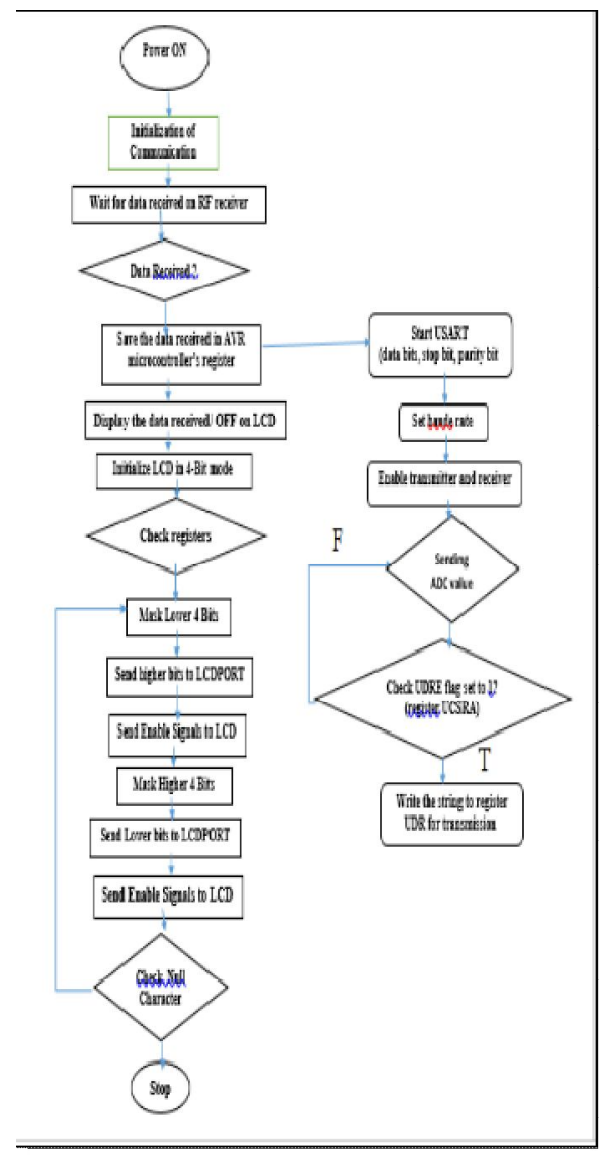

Figure 3: USART communication between two AVR microcontrollers and

\subsection{The interface of AVR with LCD}

In this part of the proposed system, the $16 \times 2$ char LCD screen utilizes 4 bits parallel interface with backlight. These 4 bits take 4 lines (for data or command) in addition to 3 control signal lines whose total is 7 lines. The steps required for this part are as follow:

1-Displaying "Hello World!!" message on the screen.

2-Interfacing the LCD to the AVR microcontroller [1] utilizing 4 Bits mode.

3-Generating and displaying "ID".

The Diagram which displays the interface of the LCD with the AVR microcontroller (ATmega32) [1] is shown in Figure 4.

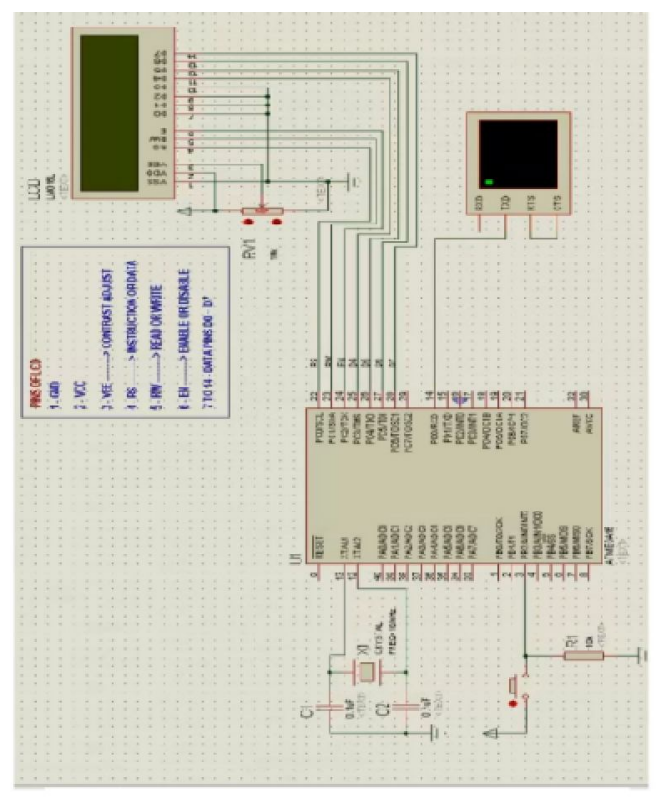

Figure 4: Block diagram of interface between AVR32A, LCD and RFID [9].

\subsection{The Interface of HC-05 Bluetooth Module with AVR ATmega32}

The device can be used in two modes; data mode and command mode. The data mode is used for data transfer between devices whereas command mode is used for changing the settings of the Bluetooth [8] module. The module works on $5 \mathrm{~V}$ or $3.3 \mathrm{~V}$. As HC-05 Bluetooth [8] module has $3.3 \mathrm{~V}$ level for RX/TX and the microcontroller can identify $3.3 \mathrm{~V}$ level, thus, no compelling reason to move transmit level of the HC-05 module. To configure HC-05 to communicate with microcontrollers [1] the default baud rate of module was 38400 . For direct communication with microcontroller, the settings of HC-05 and its baud rate are changed via Laptop and a USB-TTL converter. The connections between HC05 module \& the USB converter are as follows:

$\begin{array}{lll}\text { HC - 05 MODULE } & \text { USB-TTL MODULE } \\ \text { VCC } & \text { 5.0V } \\ \text { GND } & \longrightarrow & \text { GND } \\ \text { TXD } & \longrightarrow & \text { RXD } \\ \text { RXD } & \longrightarrow & \text { TXD }\end{array}$


$\mathrm{KEY} \quad \longrightarrow \quad 5 \mathrm{~V}$

\section{IMPLEMENTATION AND RESULTS}

The system connected using HyperTerminal software as shown in Figure 5 and Figure 6. Figure 5 shows valid attendance displaying ID and name (Client1). Figure 6 shows invalid tag with no name displayed.

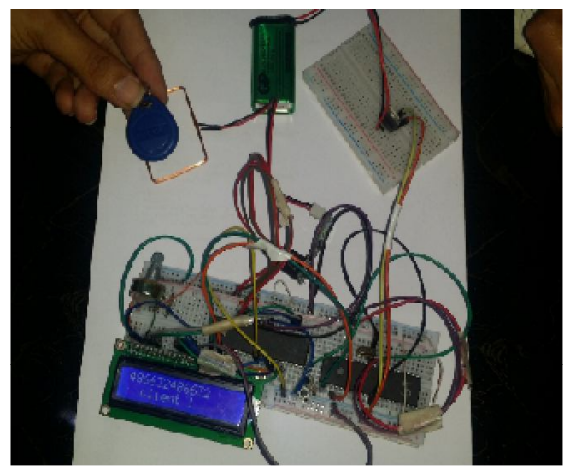

Figure 5: Embedded system project displays "client $1 "$ data

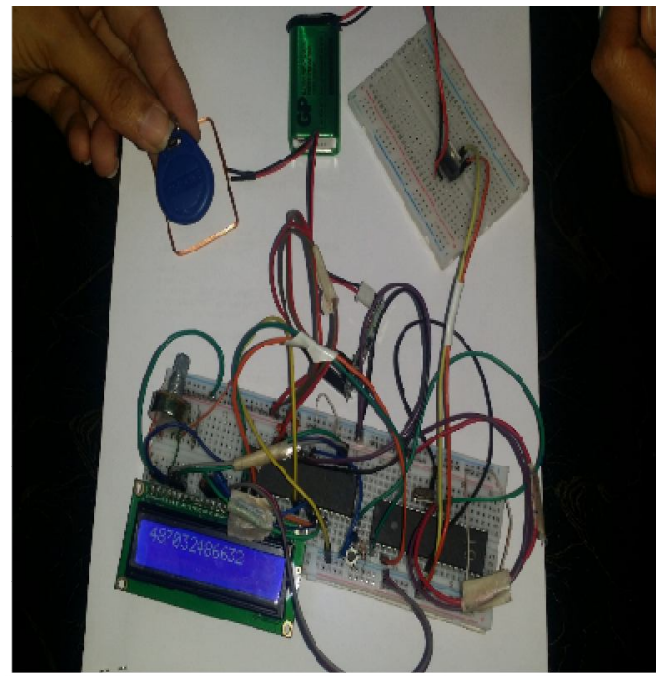

Figure 6: Embedded system project displays invalid ID without name

\section{CONCLUSION AND FUTURE WORK}

This application of Bluetooth [8] Smart concerning student attendance reduces the time spent by manual attendance, eliminates human errors and provides administrators the statistics needed for use in further managerial decisions. The developed system is implemented with embedded system framework using two Atmega AVR [1]. One AVR connected to RFID [2], [6] and LCD and the second AVR [1] interfaced to Bluetooth [8] terminal connected to mobile android. Our system can be extended in many ways. First, it may use microcontroller with more than one USART for interfacing with other devices. Second, a cloud computing database will be created to contain students' information that can be accessed from anywhere, which is scalable, available and cost efficient.

\section{REFERENCES}

[1] Zainal N.I., Sidek K.A., Gunawan T.S., and Kartiwi H.M.M. "Design and development of portable classroom attendance system based on Arduino and fingerprint Biometric", IEEE International conference on information and communication Technology for the Muslim world, 2014. https://doi.org/10.1109/ICT4M.2014.7020601

[2] Arulogun O.T., Olatunbosun A., Fakolujo O.A., and Olaniyi O.M. "RFID-Based Students Attendance Management System", International Journal of Scientific \& Engineering Research Volume 4, Issue 2, ISSN 2229-5518, 2013.

[3] Yadav D.K., Singh S., Pujari S., and Mishra P. "Fingerprint Based Attendance System Using Microcontroller and LabView", International Journal of Advanced Research in Electrical, Electronics and Instrumentation Engineering, Vol. 4, Issue 6, pp. 5111-5121, 2015 .

[4] Wang and Jingli, "The Design of Teaching Management System in Universities Based on Biometrics Identification and the Internet of Things Technology", IEEE 10th International Conference on Computer Science \& Education (ICCSE), Cambridge University, UK July 22-24, pp. 979-982, 2015.

https://doi.org/10.1109/ICCSE.2015.7250393

[5] Kamaraju M. and Kumar P.A. "Wireless Fingerprint Attendance Management System", IEEE International Conference on Electrical Computer and Communication Technologies (ICECCT), 2015.

[6] Ansari A.N., Navada A., Agarwal S., Patil S., and Sonkamble B. "Automation of Attendance system using RFID ,Biometrics, GSM modem with.Net framework”, IEEE International conference on multimedia technology, pp. 2976-2979, 2011.

[7] Benyo B., Sodor B., Doktor T., and Fordos G. "Student attendance monitoring at the university using NFC", IEEE Wireless Telecommunications Symposium (WTS), pp.1-5, 2012.

[8] Lodhaa R., Guptaa S., Jaina H., Narulaa H. "Bluetooth Smart based Attendance Management System", International Conference on Advanced Computing Technologies and Applications (ICACTA 2015), vol. 45; pp. 24-27, 2015.

https://doi.org/10.1016/j.procs.2015.03.094

[9]Tutorial 2: Making a Development Board for Atmega Series, available at

http://embeddedelectronicsforatmegaseries.blogspot.com/201 1/01/tutorial-2-making-development-board-for.html 